\title{
Bodas para uma Vida: Motivos para Manter um Casamento de Longa Duração
}

\author{
Junia Denise Alves-Silva ${ }^{1}$ \\ Fabio Scorsolini-Comin \\ Universidade Federal do Triângulo Mineiro, Uberaba, MG, Brasil \\ Manoel Antônio dos Santos \\ Universidade de São Paulo, São Paulo, SP, Brasil
}

\begin{abstract}
Resumo
O objetivo deste estudo foi investigar os motivos que levam as pessoas a manterem casamentos de longa duração. Foram entrevistados sete casais com tempo médio de casamento de 45,7 anos, com média de idade de 68,9 anos e com filhos. A partir de dois roteiros semiestruturados, os participantes foram entrevistados individualmente e em casal, totalizando 21 entrevistas. Por meio da análise de conteúdo temática, foram construídas 19 categorias com os motivos mais frequentes indicados pelos participantes para a manutenção do casamento. A responsabilidade com a família e com o cônjuge, a necessidade de cumprir o que consideram como dever de esposo/esposa e pai/mãe, além dos laços afetivos entre os familiares foram os motivos mais elencados nas entrevistas. Foi possível observar a tentativa de equilíbrio entre individualidades e conjugalidade por parte dos casais entrevistados, bem como a manutenção dos papéis de gênero ao longo dos anos de relacionamento. Devem ser fomentados novos estudos nesse tema, contribuindo para a área da conjugalidade.
\end{abstract}

Palavras-chave: Casamento, relações conjugais, motivação, velhice.

\section{Entire Life's Wedding: Reasons to Maintain a Long-Term Marriage}

\begin{abstract}
The aim of this study is to investigate the reasons why people maintain long-term marriages. We interviewed seven couples with average marriage time of 45.7 years, average age of 68.9 years old and with children. From two semi-structured scripts, the participants were interviewed individually and as a couple, totalizing 21 interviews. Through the thematic analysis of content, 19 categories were made with the most common reasons why the participants maintain the marriage. Responsibility to the family and to the spouse, the need of fulfilling what they consider as duty of a husband/wife and father/ mother, in addition to affectional bonds between the relatives were the most important reasons in the interviews. It was possible to notice the interviewed couples' attempt of balance between individualities and conjugality, as well as the maintenance of gender roles throughout the years of relationship. Further researches on this topic should be encouraged, contributing to the study of conjugality.
\end{abstract}

Keywords: Marriage, marital relations, motivation, old age.

Endereço para correspondência: Universidade Federal do Triângulo Mineiro, Programa de Pós-graduação em Psicologia, Rua Conde de Prados, 155, Nossa Senhora da Abadia, Uberaba, MG, Brasil 38025-260. E-mail: juniaalvess@hotmail.com

Financiamento: Conselho Nacional de Desenvolvimento Científico e Tecnológico (Bolsa de Pós-Doutorado Júnior ao segundo autor, Processo no 501391/2013-4, e bolsa de iniciação científica para a primeira autora) e Fundação de Amparo à Pesquisa do Estado de Minas Gerais (FAPEMIG). 


\section{Bodas para Toda la Vida: Razones para Mantener un Matrimonio de Largo Plazo}

\section{Resumen}

El objetivo de este estudio fue investigar los motivos que llevan a las personas a mantener matrimonios de larga duración. Fueron entrevistados siete parejas con tiempo medio de matrimonio de 45,7 años, con media de edad de 68,9 años y con hijos. A partir de dos guiones semiestructuradas, los participantes fueron entrevistados individualmente y en pareja, totalizando 21 entrevistas. Por medio del análisis de contenido temática, fueron construidas 19 categorías con los motivos más frecuentes indicados por los participantes para el mantenimiento del matrimonio. La responsabilidad con la familia y con el conyugue, la necesidad de cumplir lo que consideran como deber de esposo/esposa y padre/madre, además de los lazos afectivos entre los familiares fueron los motivos más enumerados en las entrevistas. Fue posible observar el intento de equilibrio entre individualidades e conyugalidad por parte de las parejas entrevistadas, así como la manutención de los papeles de género a lo largo de los años de relacionamiento. Deben ser fomentados nuevos estudios em este tema, contribuyendo para el área de la conyugalidad.

Palabras clave: Matrimonio, relaciones conyugales, motivación.

A dinâmica da conjugalidade é perpassada por aspectos individuais, familiares, históricos e sociais, sendo que o vínculo conjugal é constituído considerando toda a trajetória percorrida pelo casal, que teve início na escolha do cônjuge. Dessa forma, o casamento se apresenta como uma construção conjunta da realidade, sendo o espaço de expressão das individualidades e, ao mesmo tempo, de estruturação da conjugalidade. É necessário investir no relacionamento, a fim de que ele continue satisfatório ao longo dos anos, buscando-se o equilíbrio entre individualidade e conjugalidade (Norgren, Souza, Kaslow, Hammerschmidt, \& Sharlin, 2004). A conjugalidade pressupõe o entrelaçamento de duas histórias familiares diferentes, experiências distintas acerca do que é ser um casal, do que é ser pai/mãe e de como os filhos devem ser criados.

Desse modo, o casamento não seria apenas uma transição no ciclo vital, mas uma transformação significativa que interfere na própria redefinição das identidades de cada parceiro (Féres-Carneiro \& Diniz, 2010; Rizzon, Mosmann, \& Wagner, 2013; Scorsolini-Comin \& Santos, 2012). Diferentemente de sua função primeira de atender a interesses econômicos e sociais, a união conjugal se apresenta na contemporaneidade motivada por razões afetivas, de afinidade e proximidade, caracterizando-se como uma escolha do indivíduo (Coutinho \& Menandro, 2010).

Para Torres (2004), as mulheres e o amor seriam os protagonistas do século XX. As mulheres ultrapassaram os limites impostos socialmente pela dominação masculina e mostraram que estão dispostas a ir muito além da função materna a que foram limitadas. Já o amor foi considerado como condição necessária para a união conjugal, não somente para consagrar o seu início, mas também como elemento fundamental para sustentar o relacionamento ao longo do tempo. Essas transformações favoreceram a experiência da conjugalidade em diversas configurações, tornando o casamento tradicional mais uma possibilidade, entre tantas (Coutinho $\&$ Menandro, 2010). Consequentemente, a contemporaneidade reconhece diversas alternativas ao modelo tradicional de família, abarcando novos arranjos, por exemplo, com pais e mães trabalhando fora de casa como casais de dupla carreira, recasamentos, famílias monoparentais e homoafetivas. Essas transformações redefinem o conceito de família e também as expectativas das pessoas quanto ao casamento tradicional (Jablonski, 2010). O que vemos, atualmente, é uma ressignificação dessas instituições, com reformulações em suas características constituti- 
vas, o que tem levado à coexistência de padrões tradicionais e modernos tanto conjugais quanto familiares (Cecílio \& Scorsolini-Comin, 2013).

Unir-se a alguém por meio de um vínculo mais duradouro pode ter se tornado um dilema na vida contemporânea, visto que se vivencia um tempo marcado pelo individualismo, valorização do sucesso profissional e anseio de realização pessoal. Sob a égide desses valores, a agenda individual tem prioridade frente à pauta coletiva. Busca-se um investimento em si mesmo e um adiamento da conjugalidade, o que leva a um conflito entre a necessidade de articular a individualidade e a gestão do relacionamento amoroso. As pessoas são convidadas a buscarem cada vez mais a traduzirem suas metas, em termos de sucesso, dinheiro, amor ou felicidade (Neves, Dias, \& Paravidini, 2013). Mesmo assim, as Estatísticas do Registro Civil de 2012 (Instituto Brasileiro de Geografia e Estatística [IBGE], 2012) contabilizaram uma tendência de elevação da taxa de nupcialidade nos últimos dez anos. Embora esses dados sejam inferiores aos observados na década de 1970, essa evolução nos últimos dez anos provavelmente é decorrente das transformações nos arranjos conjugais, que têm impulsionado recasamentos, facilidades legais para o divórcio e a procura por formalizar uniões consensuais (IBGE, 2012).

Mesmo considerando as múltiplas possibilidades de ser casal e ser família, ainda se observam-se no contexto atual casamentos de longa duração, ou seja, relacionamentos que passaram incólumes pelas diversas etapas do ciclo de vida familiar e que resistiram às transformações da vida conjugal e do convívio familiar (Norgren et al., 2004). Na literatura científica, a maioria das investigações consideram longevos os casais que se mantêm unidos há, pelo menos, 15 ou 20 anos (Bachand \& Caron, 2001; Costa \& Mosmann, 2015; Norgren et al., 2004). Essas relações podem ser muito gratificantes se o casal souber conviver com as diferenças e negociar formas satisfatórias de solucionar os conflitos gerados durante o longo convívio. A manutenção da harmonia conjugal contribui para o crescimento pessoal dos cônjuges, porém é possível que a percepção do relacionamento seja diferen- te para cada casal, ou até mesmo para cada membro de um mesmo par. Como todo investimento humano complexo, o casamento é um processo dinâmico que exige permanente revisão de expectativas e remanejamento de metas.

Ao revisar a literatura internacional, observa-se uma tendência à realização de estudos com desenho quantitativo a respeito do tema, com pouca abertura para a compreensão das particularidades de cada casal, suas trajetórias evolutivas e motivações para a manutenção da conjugalidade. São priorizados estudos sobre saúde e bem-estar, notadamente com cônjuges idosos, com menor ênfase nos aspectos construídos e potencializados no domínio compartilhado da conjugalidade (Landis, Peter-Wight, Martin, \& Bodenmann, 2013; Margelisch, Schneewind, Violette, \& Perrig-Chiello, 2015; O'Leary, Acevedo, Aron, Huddy, \& Mashek, 2012). No contexto nacional são escassas as investigações sobre esses casais (Alves-Silva, Scorsolini-Comin, \& Santos, 2016; Costa \& Mosmann, 2015; Grizólio, Scorsolini-Comin, \& Santos, 2015; Paiva \& Gomes, 2006; Scorsolini-Comin \& Alves-Silva, 2016), o que revela que as especificidades desses relacionamentos têm sido pouco consideradas, tanto em termos de suas potencialidades quanto de suas necessidades. A partir dessas considerações, e tendo em vista a incipiente literatura nacional acerca do tema, o objetivo deste estudo foi investigar os motivos que levam as pessoas a manterem casamentos de longa duração.

\section{Método}

\section{Tipo de Estudo}

Trata-se de um estudo exploratório e transversal, fundamentado na abordagem de pesquisa qualitativa. Em termos éticos, este estudo faz parte de um projeto de pesquisa mais amplo sobre conjugalidade de longa duração, aprovado pelo Comitê de Ética em Pesquisa da instituição de origem da primeira autora.

\section{Participantes}

Foram incluídos como participantes casais heterossexuais em relacionamento estável (união civil ou união consensual) há pelo menos 30 
anos e que coabitassem pelo mesmo período de tempo, em primeiras núpcias, que não se separaram ao longo do tempo de união conjugal e que tivessem pelo menos um filho. Estabeleceu-se o período de mais de 30 anos por considerar que o casal, nesse estágio do ciclo de vida familiar, provavelmente já teria vivenciado a saída dos filhos de casa e superado, portanto, a parentalidade como tarefa central da família, deparando-se novamente com a companhia principal do cônjuge (Grizólio, Scorsolini-Comin, \& Santos, 2015; Ponciano \& Féres-Carneiro, 2014; Wagner, Levandowski, Gonçalves, Tronco, \& Demarchi, 2012). Não houve restrições em relação ao número de filhos do casal, grau de escolaridade, ou classificação socioeconômica, haja vista que essas variáveis não se mostraram fundamentais para a determinação da conjugalidade de longa duração, segundo estudos anteriores (Norgren et al., 2004).

Participaram do estudo sete casais, totalizando 14 participantes, com média de idade de 68,9 anos, sendo 70,1 para os homens e 67,7 para a mulheres. Predominou um baixo nível escolaridade; seis participantes não tinham completado o Ensino Fundamental. A maioria dos participantes era católica. O tempo médio de casamento foi de 45,7 anos, com 3,4 filhos por casal. Os casais 1, 2 e 6 ainda viviam com filhos em casa. O casal 3 vivia com uma neta e os casais 4, 5 e 7 viviam sozinhos. À exceção do casal 6 , todos os outros tinham netos, e os casais 4 e 5 tinham bisnetos (Tabela 1).

Tabela 1

Caracterização dos Casais Participantes do Estudo $(N=14)$

\begin{tabular}{|c|c|c|c|c|c|c|}
\hline Casal & Idade & Profissão & Escolaridade & Religião & $\begin{array}{l}\text { Tempo de } \\
\text { casamento }\end{array}$ & Filhos \\
\hline \multirow[b]{2}{*}{1} & $62(\mathrm{H})$ & $\begin{array}{l}\text { Servidor público } \\
\text { federal }\end{array}$ & $\begin{array}{l}\text { Ensino Médio } \\
\text { incompleto }\end{array}$ & Católica & \multirow[b]{2}{*}{33 anos } & \multirow[b]{2}{*}{3} \\
\hline & $59(\mathrm{M})$ & $\begin{array}{l}\text { Funcionária pública } \\
\text { municipal }\end{array}$ & Ensino Médio & Católica/Espírita & & \\
\hline \multirow{2}{*}{2} & $57(\mathrm{H})$ & Bancário & Ensino Superior & Católica & \multirow{2}{*}{33 anos } & \multirow{2}{*}{4} \\
\hline & $57(\mathrm{M})$ & Empresária & Ensino Médio & Católica & & \\
\hline \multirow{2}{*}{3} & $66(\mathrm{H})$ & Motorista & $\begin{array}{l}\text { Ensino Fundamental } \\
\text { incompleto }\end{array}$ & Espírita & \multirow{2}{*}{42 anos } & \multirow{2}{*}{3} \\
\hline & $61(\mathrm{M})$ & Do lar & $\begin{array}{l}\text { Ensino Fundamental } \\
\text { incompleto }\end{array}$ & Espírita & & \\
\hline \multirow{2}{*}{4} & $86(\mathrm{H})$ & $\begin{array}{l}\text { Lavrador } \\
\text { Aposentado }\end{array}$ & $\begin{array}{l}\text { Ensino Fundamental } \\
\text { incompleto }\end{array}$ & Espírita & \multirow{2}{*}{66 anos } & \multirow{2}{*}{4} \\
\hline & $86(\mathrm{M})$ & Dona de casa & $\begin{array}{l}\text { Ensino Fundamental } \\
\text { incompleto }\end{array}$ & Espírita & & \\
\hline \multirow{2}{*}{5} & $85(\mathrm{H})$ & $\begin{array}{l}\text { Chefe de seção } \\
\text { aposentado }\end{array}$ & $\begin{array}{l}\text { Ensino Fundamental } \\
\text { incompleto }\end{array}$ & Católica & \multirow{2}{*}{63 anos } & \multirow[b]{2}{*}{5} \\
\hline & $82(\mathrm{M})$ & Do lar & $\begin{array}{l}\text { Ensino Fundamental } \\
\text { incompleto }\end{array}$ & Católica & & \\
\hline \multirow{2}{*}{6} & $60(\mathrm{H})$ & Motorista & Ensino Médio & Católica & \multirow{2}{*}{32 anos } & \multirow{2}{*}{2} \\
\hline & $58(\mathrm{M})$ & Vice-diretora de escola & Ensino Superior & Católica & & \\
\hline \multirow[b]{2}{*}{7} & $75(\mathrm{H})$ & Comerciante aposentado & Ensino Médio & Católica & \multirow[b]{2}{*}{51 anos } & \multirow[b]{2}{*}{3} \\
\hline & $71(\mathrm{M})$ & Comerciante & $\begin{array}{c}\text { Ensino } \\
\text { Fundamental }\end{array}$ & Católica & & \\
\hline
\end{tabular}




\section{Instrumentos}

Foram utilizados dois roteiros de entrevista semiestruturada, elaborados a partir do objetivo deste estudo, sendo um aplicado individualmente a cada cônjuge e o outro aplicado ao casal. Os instrumentos foram aplicados face a face com cada um dos participantes individualmente (em um primeiro momento) e em conjunto (em um segundo momento). A aplicação dos roteiros em dois momentos distintos teve como objetivo permitir diferenciar as experiências individuais dos cônjuges, suas percepções e motivações e, posteriormente, a dinâmica do relacionamento conjugal e as vivências do casal.

\section{Procedimento}

Coleta de Dados. Os participantes foram recrutados a partir de contatos realizados em um município de médio porte do Estado de Minas Gerais e um outro do interior do Estado de São Paulo. Essas cidades têm estrutura e dinamismo socioeconômico e cultural semelhantes, e apesar de estarem localizadas em estados distintos, estão geograficamente próximas. Foram escolhidas em função dessas similaridades e também da disponibilidade de acesso aos participantes. A partir dos primeiros contatos, realizados por meio de indicações das redes dos pesquisadores, os participantes indicaram outros possíveis casais, em um procedimento conhecido como "bola de neve". Após contato telefônico, os pesquisadores apresentaram o projeto e explicaram os termos de participação. Em um primeiro momento, os entrevistados foram ouvidos separadamente, a fim de compreender as motivações individuais, por meio de um roteiro de entrevista semiestruturado. Em um segundo momento, os cônjuges foram entrevistados ao mesmo tempo para que fosse possível perceber como eles compreendiam o próprio casamento e captar a interação do par. Ao todo, foram realizadas 14 entrevistas individuais e sete com os casais, o que permitiu produzir um corpus formado por 21 entrevistas. Os participantes assinaram o Termo de Consentimento Livre e Esclarecido antes do início da coleta dos dados. As entrevistas foram realizadas em salas reservadas dos serviços-escola de Psicologia aos quais os autores estão vinculados.

Análise dos Dados. Os dados coletados foram audiogravados e transcritos na íntegra, respeitando-se a literalidade das falas. Após a transcrição do material, as entrevistas foram analisadas. Para a organização dos dados e operacionalização da análise, foram utilizados os procedimentos de análise de conteúdo temática preconizados por Bardin (1977/2002). Foram destacados os motivos mais frequentes para a manutenção do casamento, organizados por meio de categorias. Desse modo, as categorias refletem o leque de motivações elencadas pelos participantes para a manutenção da conjugalidade. Cada menção a um motivo para manter o relacionamento conjugal ou explicação para o casamento de longa duração foi anotada e, posteriormente, quantificada. Esse processo de análise resultou em 19 categorias, que correspondem às motivações ou explicações apresentadas, a partir da análise das 21 entrevistas. Embora as motivações tenham emergido mais claramente nas entrevistas individuais, foram consideradas as explicações oferecidas pelo par em interação. Esse processo não equivale a considerar os relatos produzidos pelos participantes como independentes entre si, mas significa tão somente que as motivações podem ser diversas a partir do modo como se constrói a narrativa da própria vida e do relacionamento, tanto individual como na dimensão da relação dual. Assim, as menções eram contabilizadas independentemente do momento das entrevistas em que foram narradas, priorizando os sentidos construídos pelos participantes ao longo dos dois encontros realizados com cada um.

A fim de sistematizar e potencializar a discussão dos principais resultados, as categorias mais frequentes dentre as 19 elencadas foram reagrupadas em quatro eixos temáticos: (1) Responsabilidade com a família; (2) Qualidades próprias, do outro e construídas na relação; (3) Religiosidade e espiritualidade; (4) Similaridades e complementaridades no par. A análise e interpretação dos dados foram pautadas nas 
produções científicas acerca da conjugalidade e da parentalidade, considerando a escassez de estudos específicos sobre a dinâmica dos casais longevos (Bachand \& Caron, 2001; Brasileiro, Jablonski, \& Féres-Carneiro, 2002; Costa \& Mosmann, 2015; Coutinho \& Menandro, 2010; Jablonski, 2010; Norgren et al., 2004; Paiva \& Gomes, 2006; Scorsolini-Comin \& Santos, 2012).

\section{Resultados e Discussão}

A Figura 1 apresenta as 19 categorias, que correspondem aos motivos explicitados pelos cônjuges para a manutenção do casamento. Tais categorias estão dispostas por ordem de frequência de suas menções nas entrevistas. Como destacado no Método, as categorias mais mencionadas foram agrupadas em quatro eixos temáticos para posterior análise, segundo as similaridades entre as mesmas. A seguir, os eixos temáticos serão apresentados e discutidos.

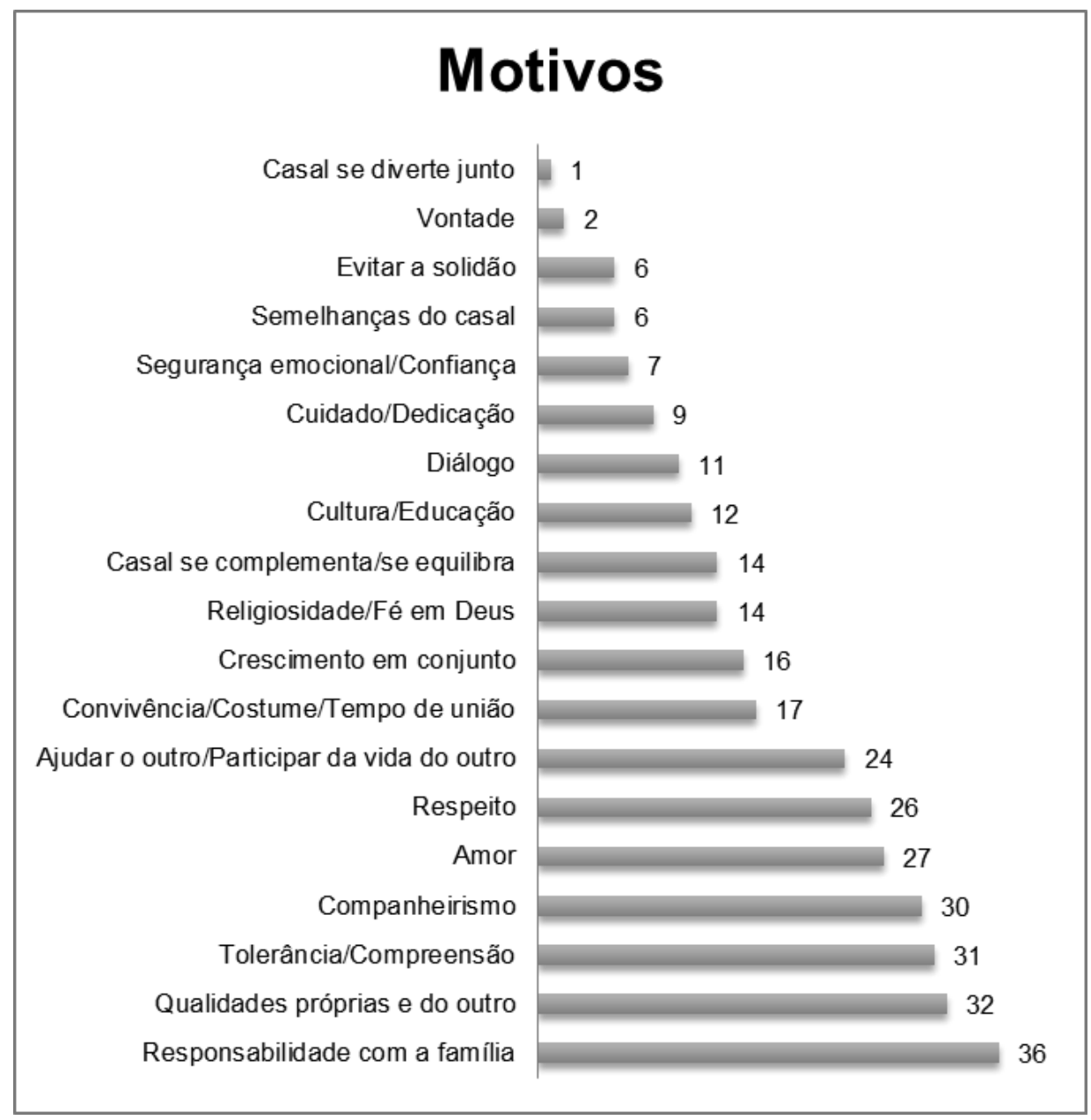

Figura 1. Motivos citados pelos entrevistados para a manutenção de um casamento ao longo dos anos, conforme a quantidade de indicações.

\section{Responsabilidade com a Família}

A responsabilidade com a família foi considerada pelo grupo entrevistado como o principal motivo para a manutenção do casamento por muitos anos. Ou seja, foi a justificativa mencionada com maior frequência, aparecendo nos relatos de 19 dos 21 entrevistados. As falas dos participantes destacaram principalmente aspectos da relação familiar, com ênfase na responsabilidade que o cônjuge sente ter em relação à família nuclear, a necessidade de cumprir o que considera como seu dever de esposo/esposa e pai/mãe, e os laços afetivos entre os familiares. 
... depois de casar, a gente tem uma responsabilidade de tirar uma, uma moça de, da casa do pai, e tem que ter uma responsabilidade pra poder... a pessoa nem pode pensar em falar em largar, né, que é uma responsabilidade que a pessoa tem e eu, se Deus quiser, até a última hora eu, a minha intenção é, até a última hora, eu quero tá junto e zelar da minha velha. (Homem 4)

"A gente adquiriu uma família. A gente adquiriu um lar. Num é uma dificuldade, uma coisa que você vai, não. É importantíssimo, uai. Se acabar o casamento, acaba a sua vida" (Homem 6).

Porque, quando você é mãe, a sua preocupação é de dar o carinho, de tá ali. O pai não, a preocupação do pai é "como é que eu vou fazer com que essa criança cresça, né", viva, educação, alimentação, é saúde. Então o pai preocupa muito com essa parte financeira. (Mulher 2)

A realidade identificada nas entrevistas é influenciada pelos papéis sociais e de gênero herdados das famílias de origem, em conformidade com a cultura e moralidade vigentes na época em que os participantes se casaram, entre as décadas de 1940 e 1980. A educação recebida quanto às responsabilidades de cada cônjuge também pode ter influenciado a maneira como esses casamentos se constituíram. Para os cônjuges entrevistados, casar era, antes de mais nada, estabelecer um vínculo de aliança indissolúvel e contrair o compromisso de cuidar da vida do outro até a morte. Enquanto o modelo de vida familiar tradicionalmente exigia que um homem se tornasse o provedor financeiro e físico da família, e a mulher assumisse o cuidado da casa e dos filhos, as relações contemporâneas mostram que esses modelos representam cada vez menos a experiência familiar (Brasileiro et al., 2002). Entre os entrevistados, foi possível observar que os casais 3, 4 e 5 vivenciaram o modelo tradicional de casamento e família, enquanto que os casais 1, 2, 6 e 7 vivenciaram um modelo misto, no qual valores tradicionais coexistem com outros, mais contemporâneos. Nesses casos, observou-se que a mulher que trabalhava fora tinha essa função como adicional, permanecendo em dupla jornada de trabalho por não se eximir da responsabilidade de cuidar da casa e dos filhos. Mesmo quando essa tarefa era delegada a uma babá ou ajudante, a responsável por sua supervisão era a mulher. Esses dados corroboram outras pesquisas realizadas no âmbito dos afazeres domésticos (Araújo \& Scalon, 2005; Jablonski, 2010; Perlin \& Diniz, 2005), nas quais os homens são vistos como coadjuvantes na responsabilidade pelas tarefas de manutenção do lar:

Ele me ajuda muito, mas ele me ajuda mais final de semana. Agora eu tô até cobrando ele, ficar cobrando assim, eu falo pra ele assim "oh, num é só final de semana que come não e nem suja roupa e tudo, né, semana inteira come e até pior, né, é mais puxado". Então às vezes ele passa um paninho na casa, faz uma coisinha, mas ajuda mesmo, muito mesmo, ele me ajuda, mas só no final de semana. (Mulher 1)

"O marido é que sustentava a casa. A mulher cuidava do lar, dos filhos em casa. O marido é que dava conta da obrigação dele" (Homem 3).

A moça, né, ela tinha que assumir a casa, saber fazer alguma coisa. Se num fizesse, tinha que aprender na marra. Erra num dia, fazer no outro dia melhor, pedindo as receita pra sogra, pra mãe e assumir mesmo, igual eu te falei, assumir o casamento. E... Acho que o rapaz era isso também, a responsabilidade de cuidar duma moça, né, que os pais recomendavam. (Mulher 7)

Os casamentos, em que apenas um dos cônjuges se encarrega do sustento da família, parecem ser cada vez menos frequentes, pois as mulheres têm se voltado para o trabalho fora de casa, o que possibilita alcançar um melhor padrão de vida para a família e também realizar objetivos pessoais relacionados à autoestima. Dessa maneira, almejar o sucesso profissional tem sido encarado como uma estratégia de realização pessoal e de garantia da independência financeira, o que assume relevância no contexto contemporâneo, já que, atualmente, os casamentos nem sempre são duradouros (Jablonski, 2010).

A dupla jornada de trabalho emerge no bojo da ressignificação do papel da mulher na família e 
na sociedade, porém ainda preservando parte dos valores tradicionais, pois é mantida a responsabilidade predominantemente feminina pelo cuidado do lar e dos filhos (Perlin \& Diniz, 2005), o que atravessou as diversas fases da conjugalidade ao longo desses anos. Isso pode indicar que, por mais que ocorram transformações nos papéis sociais e familiares, observa-se a coexistência de crenças tradicionais e contemporâneas, com certa cristalização de papéis associados ao gênero e ao modelo patriarcal. A manutenção desses papéis atravessa a constituição das famílias e é transmitida por diversos mecanismos sociais, culturais e históricos, não permitindo à mulher lançar-se em outras tarefas e receber o apoio do esposo, ou, em alguns casos, permitindo que o homem mantenha a dominação sobre a mulher, gerando uma impressão de aparente naturalidade nessas relações desiguais (Serpa, 2010). Alguns entrevistados sequer questionam se as relações entre os sexos poderiam ser diferentes, haja vista a prevalência de papéis tradicionais, legitimados no contexto dos valores familiares de origem.

Nos discursos das quatro mulheres com dupla jornada de trabalho, observou-se também a dupla função do trabalho: como uma forma de afirmação da identidade e também uma necessidade de obter o sustento financeiro da família. Em duas mulheres que se dedicaram exclusivamente ao universo doméstico, observaram-se indícios de um possível desejo/vontade de terem realizado uma função externa ao lar ao longo dos anos de casamento. Nesses casos, é possível supor que houve certa destituição feminina da capacidade de escolher no âmbito de sua relação conjugal, encontrando pouca flexibilidade do cônjuge em relação ao tema no sentido de permitir ou encorajar que a esposa trabalhasse fora de casa. Isso pode ser compreendido em um contexto social no qual o espaço da mulher estava associada ao ambiente doméstico e a função de cuidar.

O cuidado com os filhos não foi mencionado pelos casais como uma tarefa atual devido à maturidade dos mesmos. Nenhum casal tinha filhos com idade inferior a 25 anos, sendo que a maioria deles já não vive mais na casa dos pais. Relatos sobre a vida em família quando os filhos ainda eram pequenos sugerem mulheres responsáveis pelo cuidado dos filhos, alimentação e afeto, e homens responsáveis pela manutenção da disciplina - nos casos em que o comportamento das crianças fugia ao controle materno, o pai era chamado para resolver a situação, geralmente utilizando de métodos corretivos mais intimidadores. Desse modo, o papel masculino, nesse grupo entrevistado, se mostrou complementar ao da mulher quanto à educação dos filhos, mas igualmente cristalizado em funções essencialmente relacionadas à divisão binária dos gêneros, com poucas alternativas de ruptura de um modelo naturalizado como tradicional.

"Ai veio os filho e tinha aquela problema de perguntar 'havia atrito entre vocês dois no casamento?'. Havia, mas havia por causa dos filho. Porque era eu e ela cuidar de cinco filho, num é fácil" (Homem 5).

"Depois logo vem os filho que já é uma nova adaptação, cada dia você tá aprendendo uma coisa nova" (Homem 6).

Bachand e Caron (2001) realizaram um estudo qualitativo com 15 casais de Maine, EUA, casados por um período entre 38 e 54 anos e pais de pelo menos um filho. Entre os questionamentos que foram feitos aos participantes, um deles referiu-se à influência dos filhos na relação conjugal. Segundo as autoras, 30 entrevistados indicaram que o nascimento dos filhos trouxe certa coesão ao casamento e reforçou o laço conjugal, sendo que 16 deles mencionaram ainda algum tipo de estresse e/ou período de adaptação à nova realidade. Os casais entrevistados no presente estudo demonstram que o nascimento dos filhos significou um momento de alegria, mas que também exigiu adaptações. No que se refere à conjugalidade, a transição para a parentalidade parece ter afetado o relacionamento a dois, conforme referido no excerto de fala do entrevistado 5 .

Tornar-se pai e mãe apresenta-se como um período de incertezas e desafios ao casal, o que envolve a necessidade de adotar medidas flexíveis para lidar com o imprevisível e ter habilidades de negociação para lidar com as arestas que podem aparecer no relacionamento conjugal (Cecílio \& Scorsolini-Comin, 2013; Prati \& Koller, 2011). A maternidade e a paternidade 
exigem que os indivíduos assumam novos papéis sociais, o que também cobra uma adaptação das identidades individuais e da identidade conjugal (Brasileiro et al., 2002; Ponciano \& Féres-Carneiro, 2014). Desse modo, corroborando os estudos mencionados, o presente estudo destaca que a parentalidade tem repercussões na conjugalidade, mas é preciso ressalvar que tais investigações não se centraram nos casamentos de longa duração, o que deve ser aprofundado em estudos vindouros. As possíveis discordâncias em relação à criação dos filhos emergiram no processo de transição para a parentalidade ou quando os filhos eram menores, indicando também um amadurecimento do casal ao longo dos anos e melhor manejo de conflitos decorrentes de situações problemáticas vivenciadas com os filhos.

\section{Qualidades Próprias, do Outro e Construídas na Relação}

Esse eixo temático recupera as menções às características que o(a) entrevistado(a) considerou serem positivas em si mesmo e no(a) companheiro(a) e que favoreceram a manutenção da conjugalidade. As falas colocaram em foco a demonstração de afeto, desejar o bem ao outro, ser carinhoso, trabalhador, honesto, ter controle das próprias emoções, ser verdadeiro, otimista, carismático, humilde e não se desesperar diante das dificuldades encontradas. Essas características são essencialmente individuais, de modo a configurar atributos observados e valorizados pelo cônjuge.

Quando você ver a pessoa triste, tristonha, perguntar o porquê. Você conhecer aquilo da pessoa, um pouco da pessoa. Você olha assim, parece que a pessoa tá bem, mas num tá, porque você conhece. Então isso é que mantém os laços. É dizer aquele "te amo", "você é importante pra mim". Então tanta coisinha pequenininha que às vezes assim a gente não julga que seja necessário, mas que é necessário na vida dum casal. (Mulher 2)

Também se enquadrou nesse eixo a menção ao exercício cotidiano da tolerância e compreensão, em que se observou a relevância que o en- trevistado dá a essas atitudes no relacionamento. $\mathrm{O}$ mesmo destaque para fatores conjugais foi dado aos eixos subsequentes, sendo eles "companheirismo", "amor" e "respeito mútuo". Essas motivações podem ser consideradas relacionais, ou seja, construídas a partir da interação com o par, de modo a representar características da própria relação. As falas dos entrevistados trazem indicações do vínculo conjugal, ou seja, da intimidade e parceria que sentem manter com o cônjuge, do amor que une o casal e do respeito mútuo entre os cônjuges, considerando questões emocionais, materiais e relacionais.

Casamento, na verdade, é você exercitar a tolerância. Você saber se tolerar, saber tolerar a pessoa que tá do seu lado, entendeu. Porque se não houver tolerância, se não houver assim uma, uma convivência, digamos assim, com as frustrações, porque tudo na vida não é um mar de rosas todo dia, então existem muitas frustrações. Se você não conseguir lidar com frustração e não ter, vamos dizer assim, um, uma tranquilidade, uma calma pra resolver as coisas sem discussão, você briga todo dia. O casamento é isso. (Homem 2)

A gente vive pela vida, pelo amor que a gente tem um pro outro porque, quando na época que a gente casa, fala assim "ah, quando casa tá novinho, o amor...”. Não, tá certo, é uma fase que passou e no dia a dia a gente vem, vem, vem, a gente se... fica igual agora, os filho casou, saiu, os neto vem de vez em quando, é só eu e ela. É eu por ela, ela por mim e Deus por nós. (Homem 3)

Em pesquisa realizada com jovens, examinando os fatores responsáveis pela duração do casamento, os aspectos mais valorizados foram, pela ordem de frequência: respeito mútuo, amor, confiança, companheirismo e sexo (Jablonski, 2003). Apesar de o universo investigado ser de camadas médias - portanto, diferente do contexto social dos casais do presente estudo - os dados obtidos com os jovens se aproximam dos resultados desta pesquisa, considerando que os fatores confiança, companheirismo, amor e respeito mútuo também são citados pelos entrevistados como motivos importantes para manter um 
casamento, sendo que os três últimos apareceram entre os seis mais valorizados. Assim, jovens que ainda não se casaram e casais de longa duração parecem valorizar aspectos semelhantes em relação ao cônjuge e ao estabelecimento de um vínculo de compromisso. Dada a escolha por casamentos de longa duração, observa-se que os casais investigados se encontram dentro do modelo tradicional de família. Por isso deve-se ter cautela quando da comparação com resultados de pesquisas envolvendo casais jovens, já influenciados pelas novas configurações familiares, novos papéis de gênero e outros modos de relação homem-mulher - distanciando-se justamente do modelo da família patriarcal que os casais da pesquisa encarnam.

Deve-se pontuar que, no presente estudo, a sexualidade não foi valorizada - pelo menos não foi expressa de forma direta nos relatos individuais, nem do casal, mesmo sendo uma dimensão de relativa importância para a manutenção da relação conjugal e da qualidade de vida, até mesmo considerando as questões fisiológicas e do bem-estar psicológico (Hinchliff \& Gott, 2004). Apesar disso, vale ressaltar a possibilidade de que a atividade sexual não seja um atributo intrínseco ou necessário para garantir a solidez dos casamentos de longa duração, segundo a concepção dos entrevistados, de modo que não a inseriram como um motivo que favorece a manutenção de um relacionamento amoroso por várias décadas. $\mathrm{O}$ único momento em que a temática foi abordada durante as entrevistas foi quando o casal 6 mencionou o respeito mútuo como fator importante, considerando que os parceiros deveriam se respeitar inclusive no sexo. Segundo Jablonski (2010), é possível que os sujeitos acreditem que o sexo é uma parte integrante óbvia do casamento e que, por isso, não precisa ser explicitada ou que ele não é um fator importante para a manutenção do relacionamento, o que, segundo o autor, parece pouco provável.

A primeira coisa no casamento, se não tiver o respeito, uma coisa assim que eu te falei, o respeito é a base todinha, a base sólida do casamento tá no respeito. Todo tipo de sentimento, no amor, na tolerância... no sexo. No sexo, tudo aquilo que você sentir. Se num tiver respeito... (Homem 6 e Mulher 6 ) Segundo Hinchliff e Gott (2004), por se tratar de um tema sensível, é possível que os idosos sejam reticentes quanto a discutir abertamente a temática do sexo e a importância que ele tem em suas vidas. Ou seja, os códigos culturais que envolveram sua criação não permitiam que o sexo fosse discutido abertamente, ou haveria a possível interiorização de um estereótipo social de que pessoas mais velhas deveriam suprimir suas necessidades sexuais, ou mesmo negar sua sexualidade por temor do julgamento e da censura alheia. Na presente amostra, a questão da sexualidade não emergiu também quando os participantes abordaram o tempo em que se casaram, ainda bastante jovens, de modo que a temática pode ser considerada ainda de difícil acesso, possivelmente um tabu ou uma dimensão que pertence apenas à intimidade da díade e que não deve ser compartilhada com mais ninguém.

Considerando que a entrevistadora era jovem quando ocorreu a coleta de dados, é possível questionar se os participantes se sentiram à vontade para discutir assuntos delicados, como o papel da sexualidade na vida do casal, devido à expressiva diferença de idade existente. Ou seja, o fato da pesquisadora ser de geração diferente torna-se outra possível explicação para o fato dos assuntos referentes ao comportamento sexual ter sido mencionado apenas por um casal, e justamente o que tinha o menor tempo de união conjugal entre os entrevistados. Por outro lado, nenhum participante expressou desconfortos, pelo menos aparentemente, com qualquer pergunta formulada durante as entrevistas. Nenhum entrevistado se opôs a qualquer questão formulada. Os roteiros de entrevista não continham questões que mencionavam diretamente a sexualidade do casal. Além disso, muitos entrevistados relataram ser a primeira vez que falavam a respeito de seu casamento.

\section{Religiosidade e Espiritualidade}

Essa categoria agrupou falas em que os entrevistados mencionavam a fé e o compromisso assumido frente à religião como motivos importantes para a manutenção do casamento. A menção ao apoio das instituições religiosas foi pouco 
frequente entre os participantes. Porém, considerando que a maioria dos entrevistados professa a religião católica, é possível que haja influência da crença da indissolubilidade do matrimônio veiculada pelo catolicismo, apoiando os casais a encararem o casamento como uma parceria a ser mantida por toda a vida. Norgren et al. (2004) encontraram em sua pesquisa que todos os casais que se consideravam satisfeitos com seus relacionamentos de longa duração eram católicos praticantes, o que, segundo as autoras, pode indicar que esses cônjuges estavam, de fato, comprometidos com a impossibilidade de dissolução da união abençoada por Deus e sacramentada pela Igreja.

"É, eu continuo porque eu acho que é um compromisso que eu tenho, né, um compromisso que eu peguei perante a Deus e eu tenho que continuar ele até a última hora, se Deus quiser" (Homem 4).

"Casei, igual, faz o juramento na frente do padre pro casamento durar pra sempre e eu tenho sempre essa conviç̧ão comigo que o casamento é pra sempre, num tem esse..." (Homem 6).

O movimento expresso nessas falas revela alguns aspectos da religiosidade e da espiritualidade como fatores que contribuem para sedimentar o vínculo conjugal. Os participantes, em função de sua crença religiosa, atribuem uma dimensão transcendental ao casamento, considerado um sacramento dentro da tradição católica. A religiosidade também pode ser uma das estratégias de enfrentamento das dificuldades do casamento ao longo dos anos. Há notória influência dos dogmas religiosos, como a indissolubilidade do vínculo devido a um compromisso assumido perante a instituição religiosa e a comunidade.

Embora todos os casais entrevistados tenham manifestado satisfação com o relacionamento - e talvez, por isso, desejassem compartilhar suas experiências, há que se considerar que a "proibição" do divórcio poderia ser uma motivação para o casamento de longa duração, ou mesmo uma explicação para a não dissolução conjugal. Esse compromisso, no entanto, não é denotado pelos participantes como algo negativo, mas sim como um indicador de responsabi- lidade e o destaque para a necessidade de que os casais encontrem formas mais adequadas de resolução de conflitos, por exemplo. Entre essas estratégias pode-se incluir o diálogo, o cuidado mútuo, a dedicação, a segurança emocional e a confiança, consideradas ferramentas importantes que favoreceram a manutenção do casamento.

"E o diálogo. Tudo que você tiver de falar, não deixar pro outro dia, tem que esclarecer na hora, se possivel os dois dentro dum quarto, não falar..." (Mulher 7).

"Igual, às vezes ele pensa de um jeito, a gente pensa de outro, mas a gente tem que ter, como se diz, o respeito e acordo pra gente chegar num ponto em comum..." (Mulher 3).

Ainda em relação ao eixo religiosidade e espiritualidade, destaca-se que esse domínio pode ser importante para a manutenção do casamento justamente por não focar exclusivamente no casal, e ampliar o entendimento de que muitas das resoluções da vida pessoal não precisam ser tomadas apenas pelo par em interação, mas podem ser compartilhadas com outros grupos, outras redes de apoio e relação social. Nesse movimento, não apenas as crenças religiosas conferem um sentido mais amplo ao relacionamento, mas também permitem a formação de uma rede de apoio social como a mencionada no relato a seguir:

E outra coisa que me ajudou muito no casamento foram os movimentos de Igreja que têm o grupo de casal e a gente......E aí esses cursos me ajudou muito a ter mais fé, mais vontade de trabalhar. Eu acho que a religião é muito importante, qualquer uma que fale em Deus eu acho que é importante pra vida de casal. (Mulher 7)

O curso mencionado pela entrevistada é uma oportunidade por meio da qual os cônjuges podem expressar algumas de suas dificuldades em um grupo homogêneo, composto apenas por casais religiosos. É possível, desse modo, conhecer as experiências de outras pessoas e os modos com que elas solucionam problemas cotidianos do casamento. $\mathrm{O}$ acesso à experiência do outro, juntamente com o fato de que esses casais comungam a mesma fé, constitui um recurso para a compreensão dos conflitos vivenciados e para 
a busca de novas formas de ser e de estar em uma relação. Apesar de a religiosidade oferecer uma fonte de apoio no manejo do cotidiano conjugal, o mesmo domínio parece selar, para esses participantes, um compromisso que não pode ser alterado ou cindido, promovendo movimentos de acomodação e minimização dos conflitos ao longo do tempo (como crises no momento do nascimento dos filhos, para alguns casais), mas com pouca possibilidade de transformação ou mesmo de ruptura dos padrões reproduzidos.

\section{Em Busca de Similaridades e Complementaridades no Par}

Os participantes trouxeram indicações de características que valorizam como favorecedoras de complementaridade entre os cônjuges, considerando a importância de equilibrar o que há em um e o que falta no outro como motivo para a manutenção do casamento ao longo dos anos, corroborando os apontamentos de Paiva e Gomes (2006). As semelhanças observadas entre os parceiros também foram mencionadas, porém com menor frequência, considerando certas características e formas de agir similares entre os cônjuges que podem favorecer a união.

"Num é que a gente tem que ser igualzinho né. Igual, às vezes ele pensa de um jeito, a gente pensa de outro, mas a gente tem que ter, como se diz, o respeito" (Mulher 3 ).

É por mim, é por ela que é, além de ser esposa, é amiga, é fiel e ama a família que tem, os filho, os neto, vive pela vida, gosta de viver igual eu, também sou do mesmo jeito. Trabalho, gosto de trabalhar, gosto das coisa tudo no lugar, igual ela. (Homem 3)

No presente estudo, a busca por complementaridades superou a valorização das semelhanças entre o casal, tendo sido mencionadas 14 vezes durante as entrevistas, em comparação com as seis vezes em que as similaridades apareceram. Esse resultado aproxima-se do encontrado por Paiva e Gomes (2006). Os casais duradouros do presente estudo já vivenciaram diversas fases do ciclo vital, o que pode ter modificado ou confirmado determinadas crenças e expectativas que tinham antes de se casarem. O ideal de complementaridade parece reforçar a necessida- de social, vigente à época em que esses casais se uniram, de construção de uma família, o que passava, inequivocamente, pela legitimação do enlace conjugal como primeiro movimento no sentido de composição de um novo arranjo.

Evitar a solidão também apareceu como um motivo relevante para a manutenção do casamento, haja vista que o enlace permite a ampliação da família, o que implica em maior número de vínculos que, consequentemente, tornaria menos provável o desamparo e abandono da pessoa e o seu isolamento social. No exame das falas dos entrevistados, observou-se que o cônjuge e os filhos que vieram são considerados como companhias que impedem que a pessoa se sinta sozinha ou abandonada. Corroborando os achados de Féres-Carneiro e Diniz Neto (2010) e Jablonski (2005), a identificação do casamento como uma aliança que "afasta a solidão" foi mencionada mais por homens na presente pesquisa, tendo sido evocada por três homens e duas mulheres (cinco dos 14 participantes). É importante ressaltar que as pesquisas mencionadas nesse parágrafo contavam com amostra de jovens solteiros, considerando, portanto, sua visão e expectativas em relação à vida, enquanto o presente trabalho foi realizado com casais unidos havia mais de 30 anos. As percepções dos participantes do presente estudo são influenciadas pelas vivências do relacionamento conjugal duradouro. Além disso, o contexto no qual o presente estudo foi realizado deve ser novamente considerado, haja vista que a maioria dos filhos dos casais entrevistados residem na mesma cidade ou próximos da residência dos pais, de modo a favorecer uma vinculação mais presente no cotidiano.

De modo geral, observa-se que esses casais se uniram em uma época na qual a dissolução do matrimônio era um evento raro e, aliado aos valores cristãos professados e a um contexto interiorano e bastante tradicional, as motivações para a manutenção do casamento acabaram sendo, de certa maneira, naturalizadas. Um dos pilares que sustentam essas uniões duradouras é a crença de que não se pode romper um compromisso assumido diante da sociedade, da família de origem e da instituição religiosa. Esse interdito parece 
atravessar as demais motivações mencionadas. As características pessoais e relacionais, embora valorizadas, parecem estar submetidas ao jugo da explicação principal, ou seja, da responsabilidade e do compromisso.

Esses achados são congruentes com o estudo de Paiva e Gomes (2006), também realizado com casais longevos, no qual foi referido um modelo tradicional de casamento, colocando relevo na estruturação da família em detrimento da própria conjugalidade. Tal aspecto emergiu no presente estudo com a valorização do compromisso social e com a construção da família, de modo que a conjugalidade passou a ser naturalizada como um aspecto constitutivo dessa estruturação. É lícito afirmar, a partir dessas considerações e da análise empreendida, que os casamentos duradouros reforçam a noção tradicional de família, esmaecendo as necessidades e potencialidades da conjugalidade. Compreender a conjugalidade de longa duração passaria, portanto, pela necessidade de apreender como essa noção se estrutura diante de necessidades mais prementes, como a solidificação da família ou o compromisso com a criação dos filhos e perpetuação do lar centralizado no casal parental (Ponciano \& Féres, Carneiro, 2014; Wagner et al., 2012).

\section{Considerações Finais}

Os dois contextos nos quais os participantes da pesquisa foram recrutados apresentam similaridades, o que afasta a hipótese de uma possível diversidade cultural entre os participantes. A amostra é bastante homogênea do ponto de vista do background socioeducacional, econômico e religioso dos participantes.

Os resultados deste estudo indicaram a responsabilidade com as funções ligadas à reprodução social da família como o motivo mais frequente para a manutenção de um casamento de longa duração. Destaca-se a considerável influência de condicionantes históricos e sociais, como os que conformam os papéis de gênero, apesar da coexistência, na contemporaneidade, de valores tradicionais e modernos nas concep- ções de casal e família. Mesmo com a compreensão do casamento como uma construção conjunta, é possível que esse vínculo tenha um sentido diferente para cada casal ou ainda para cada indivíduo, o que esclarece por que membros de um mesmo casal indicaram motivos diferentes para manter sua união. Também por essa razão os motivos encontrados nesse grupo não podem ser generalizados para todas as relações conjugais duradouras.

Apesar de o motivo mais frequente remeter ao relacionamento familiar, as categorias elencadas fazem referência principalmente ao relacionamento conjugal, indicando assim que, para esse grupo, é a vinculação com o parceiro que favorece a manutenção do casamento por tantos anos. Entretanto, observa-se uma tentativa de equilíbrio entre individualidades e conjugalidade, o que se expressa na questão do trabalho, da parentalidade e do próprio modo como cada parceiro atualiza suas heranças familiares e analisa sua família de origem.

Entre as limitações deste estudo destaca-se que os participantes foram selecionados em cidades interioranas, reconhecidas como tradicionais em termos da manutenção de valores familiares. Além disso, a idade é outra variável relevante para explicar o apego a uma visão convencional da realidade, pautada em valores consagrados em período anterior à turbulenta década de 1960. Por fim, a amostra ser homogênea em termos religiosos (cristãos), o que pode ter contribuído para a explicitação de motivos para a manutenção do casamento que extrapolam a relação a dois e a inserem em um contexto social e cultural mais amplo. $\mathrm{O}$ casamento adquire, assim, um sentido existencial, permitindo a materialização da relação com o sagrado por meio das boas ações, como cuidar do(a) companheiro(a), ser leal e tolerar as frustrações do cotidiano. A profissão de fé nos valores conservadores ajuda a solidificar a coesão do casal e propicia que os cônjuges se sintam conectados com a dimensão imaterial da vida. Isso não impediu que os participantes pudessem refletir sobre seus relacionamentos, expressando alguns aspectos da intimidade do casal. 
Espera-se que este estudo possa contribuir para a compreensão dos aspectos que interferem na dinâmica de casamentos duradouros. Investigações com esse escopo podem ampliar a visibilidade desses relacionamentos na agenda de pesquisas da área de conjugalidade. Trata-se de um movimento recente, mas potencializador de novas compreensões sobre a família e o casal. Em estudos futuros, as particularidades desses arranjos podem ser relacionadas a questões de saúde mental, resiliência e enfrentamento dos estressores da vida conjugal. Ou mesmo em termos de apoio psicológico, a exemplo dos estudos internacionais (Margelisch et al., 2015), de modo a ampliar o repertório de conhecimento sobre os fatores mantenedores de um casamento. Acredita-se que compreender as motivações desses casais pode oferecer apontamentos preciosos para o planejamento de intervenções e novas pesquisas nos campos dos estudos sobre família e desenvolvimento humano.

\section{Referências}

Alves-Silva, J. D., \& Scorsolini-Comin, F. (2016). Casamentos de longa duração: apontamentos a partir da Psicologia Positiva. In B. L. Seibel, M. Poletto, \& S. H. Koller (Orgs.), Psicologia Positiva: teoria, pesquisa e intervenções (pp. 267-287). Curitiba: Juruá.

Alves-Silva, J. D., Scorsolini-Comin, F., \& Santos, M. A. (2016). Conjugalidade e casamentos de longa duração na literatura científica. Contextos Clínicos, 9(1), 32-50.

Araújo, C., \& Scalon, C. (2005). Gênero, família e trabalho no Brasil. Rio de Janeiro, RJ: Fundação Getúlio Vargas.

Bachand, L. L., \& Caron, S. L. (2001). Ties that bind: A qualitative study of happy long-term marriages. Contemporary Family Therapy, 23(1), 105-121.

Bardin, L. (2002). Análise de conteúdo (L. A. Reto \& A. Pinheiro, Trads.). Lisboa: Edições 70. (Original publicado em 1977)

Brasileiro, R. F., Jablonski, B., \& Féres-Carneiro, T. (2002). Papéis de gênero e a transição para a parentalidade. Psico, 33(2), 289-310.
Cecílio, M. S., \& Scorsolini-Comin, F. (2013). Relações entre conjugalidade e parentalidades adotiva e biológica. Psico, 44(2), 245-256.

Costa, C. B., \& Mosmann, C. P. (2015). Relacionamentos conjugais na atualidade: Percepções de indivíduos em casamentos de longa duração. Revista da SPAGESP, 16(2), 16-31.

Coutinho, S. M. S., \& Menandro, P. R. M. (2010). Relações conjugais e familiares na perspectiva de mulheres de duas gerações: "que seja terno enquanto dure". Psicologia Clínica, 22(2), 83106.

Féres-Carneiro, T., \& Diniz Neto, O. (2010). Construção e dissolução da conjugalidade: Padrões relacionais. Paidéia (Ribeirão Preto), 20(46), 269-278. doi:10.1590/S0103$863 X 2010000200014$

Grizólio, T. C., Scorsolini-Comin, F., \& Santos, M. A. (2015). The perception of parething couples engaged in long term marriages. Psicologia em Estudo, 20(4), 663-674.

Hinchliff, S., \& Gott, M. (2004). Intimacy, commitment, and adaptation: Sexual relationships within long-term marriages. Journal of Social and Personal Relationships, 21(5), 595-609.

Instituto Brasileiro de Geografia e Estatística. (2012). Estatística do Registro Civil 2012. Rio de Janeiro, RJ: Autor.

Jablonski, B. (2003). Afinal, o que quer um casal? Algumas considerações sobre o casamento e a separação na classe média carioca. In T. Féres-Carneiro (Ed.), Família e casal: Arranjos e demandas contemporâneas (pp. 141-168). Rio de Janeiro, RJ: Loyola.

Jablonski, B. (2005). Atitudes de jovens solteiros frente à família e ao casamento: Novas tendências? In T. Féres-Carneiro (Ed.), Família e casal: Efeitos da contemporaneidade (pp. 93-110). Rio de Janeiro, RJ: Pontifícia Universidade Católica do Rio de Janeiro.

Jablonski, B. (2010). A divisão de tarefas domésticas entre homens e mulheres no cotidiano do casamento. Psicologia: Ciência e Profissão, 30(2), 262-275.

Landis, M., Peter-Wight, M., Martin, M., \& Bodenmann, G. (2013). Dyadic coping and marital satisfaction of older spouses in long-term marriage. GeroPsych, 26(1), 39-47. 
Margelisch, K., Schneewind, K. A., Violette, J., \& Perrig-Chiello, P. (2015). Marital stability, satisfaction and well-being in old age: Variability and continuity in long-term continuously married older persons. Aging \& Mental Health, 1-10. doi:10.1080/13607863.2015.1102197

Neves, A. S., Dias, A. S. F., \& Paravidini, J. L. L. (2013). A psicodinâmica conjugal e a contemporaneidade. Psicologia Clínica, 25(11), 73-87.

Norgren, M. B. P., Souza, R. M., Kaslow, F, Hammerschmidt, H., \& Sharlin, S. A. (2004). Satisfação conjugal em casamentos de longa duração: Uma construção possível. Estudos de Psicologia (Natal), 9(3), 575-584.

O’Leary, K. D., Acevedo, B. P., Aron, A., Huddy, L., \& Mashek, D. (2012). Is long-term love more than a rare phenomenon? If so, what are its correlates? Social Psychological and Personality Science, 3(2), 241-249.

Paiva, M. L. S. C., \& Gomes, I. C. (2006). Casamentos duradouros: O uso de entrevistas e o TAT na análise psicanalítica da relação conjugal. $M u$ danças: Psicologia da Saúde, 14(2), 151-159.

Perlin, G., \& Diniz, G. (2005). Casais que trabalham e são felizes: Mito ou realidade? Psicologia Clínica, 17(2), 15-29.

Ponciano, E. T., \& Féres-Carneiro, T. (2014). Relação pais-filhos na transição para a vida adulta, autonomia e relativização da hierarquia. Psicologia: Reflexão e Crítica, 27(2), 209-218.
Prati, L. E., \& Koller, S. H. (2011). Relacionamento conjugal e transição para a coparentalidade: Perspectiva da psicologia positiva. Psicologia Clínica, 23(1), 103-118.

Rizzon, A. L. C., Mosmann, C. P., \& Wagner, A. (2013). A qualidade conjugal e os elementos do amor: Um estudo correlacional. Contextos Clínicos, 6(1), 41-50.

Scorsolini-Comin, F., \& Santos, M. A. (2012). Correlations between subjective well-being, dyadic adjustment and marital satisfaction in Brazilian married people. The Spanish Journal of Psychology, 15(1), 166-176.

Serpa, M. G. (2010). Perspectivas sobre papéis de gênero masculino e feminino: Um relato de experiência com mães de meninas vitimizadas. Psicologia \& Sociedade, 22(1), 14-22.

Torres, A. (2004). Casamento: Tempos, centramento, gerações e gênero. Caderno $C R H, 17(42), 405-$ 429.

Wagner, A., Levandowski, D. C., Gonçalves, J. S., Tronco, C. B., \& Demarchi, K. A. (2012). Projetos para os filhos e estratégias de socialização: A perspectiva de pais e mães. Psicologia \& Sociedade, 24(1), 122-129. 